\title{
Homicides and maltreatment-related deaths of disabled children: A systematic review
}

\begin{abstract}
This article aims to systematically review the empirical literature in relation to the homicides and maltreatment-related deaths of disabled children [PUBLISHER - THE PRECEDING UNDERLINED TEXT IS FOR THE MARGIN] to better understand risk factors and to assess support for the explanatory theories posited. These theories include: 1) the stress of caregiving; 2) altruistic intent; 3) lack of bonding with the child; 4) the challenging behaviours of a child; 5) cultural beliefs about disability; and, 6) evolutionary imperatives. Systematic searching techniques were used to retrieve relevant research articles in six electronic databases: AMED, CINAHL, Criminal Justice Abstracts, Medline (PubMed), PsycINFO and SCOPUS. The issue of a child being disabled was identified as a risk factor in most articles reviewed, however the definition of the term 'disability' was not consistent nor was there a consistent approach to recording children's disability. A range of potential risk factors were found, related to the child, the perpetrator and the environment, with the pathway to harming the child involving an interactive process between each of these. The stress of caregiving and altruistic theories were the two most common explanations, although a combination of theories may provide a more comprehensive explanation of these complex events.
\end{abstract}

\section{Key Practitioner Messages}

This is the author manuscript accepted for publication and has undergone full peer review but has not been through the copyediting, typesetting, pagination and proofreading process, which may lead to differences between this version and the Version of Record. Please cite this article as doi: $10.1002 /$ car.2574

This article is protected by copyright. All rights reserved. 
- Coordination of clear care pathways for families with disabled children, including provision of support and counselling.

- Improved professional awareness of the needs of disabled children and understanding that these needs may not coincide with those of their parents or carers.

- $\quad$ Provision of opportunities for respite to enable parents of disabled children to continue their task of caring.

- Need for consistent data on disabled children to be collected through existing child death review processes and the criminal justice system.

\section{Key words}

child death; filicide; fatal abuse; disabled children; systematic review

This article is protected by copyright. All rights reserved. 


\section{Introduction}

This article seeks to review the empirical literature regarding the homicides and maltreatment-related deaths of disabled children in three particular circumstances: (a) intentional filicides; (b) deaths directly caused by abuse or neglect (either one-off incidents, or the culmination of chronic maltreatment); or (c) deaths where abuse and neglect may have contributed but were not the primary cause of death.

In conducting this review, we wish, firstly, to better understand risk factors related to the deaths of these children and, secondly, to assess the empirical support for six proposed explanatory theories. To our knowledge, there has been no other systematic review of research regarding the deaths of disabled children in the aforementioned circumstances.

In this paper we have chosen to use the term disabled children rather than children with disabilities. This reflects the social model of disability, seeing individuals as having impairments, but being disabled by social factors. Disability is thus not just a health problem (United Nations Convention on the Rights of People with Disabilities, 2007).

\section{Greater vulnerability of disabled children to abuse}

Research has shown that, compared to non-disabled children, disabled children are three to four times more likely to be treated violently (Jones et al., 2012). Taylor et al. (2016) have summarised a range of factors identified as explaining the increased vulnerability to abuse for disabled children: disabled children may be seen by possible offenders as less knowledgeable or aware of inappropriate behaviour than a non-disabled child; impairments in 
their ability to communicate may reduce the capacity for a disabled child to disclose abuse; mobility difficulties may limit a disabled child's capacity to avoid an abuser; and, a disabled child's need for personal care may create opportunities for others to abuse them. Furthermore, factors within their family may include: stressful demands associated with the care of a disabled child; negative feelings about having a disabled child; and, behaviour management methods used by parents which may be inappropriate. Other vulnerability factors include disabled children's voices being unheard, both due to lack of engagement by professionals, and to a focus by professionals on the needs of parents, as though their needs were synonymous with their children's, resulting in professionals not looking for signs of abuse or hearing disclosures from children (Jones et al., 2017; Stalker et al., 2015; Taylor et al., 2015).

Within the literature on the homicides and maltreatment-related deaths of children, disabled children have been identified as likely to experience a greater risk [PUBLISHER THE PRECEDING UNDERLINED TEXT IS FOR THE MARGIN] (Chance and Scannapieco, 2002; Jonson-Reid et al., 2007; Koenen and Thompson, 2008). The main theories proposed to explain this increased risk relate to:

1. The stress of caregiving

2. Altruistic intent

3. Lack of bonding with the child

4. The challenging behaviours of a child

5. Cultural beliefs about disability

6. Evolutionary imperatives 
Each of these theories is summarised below.

\section{Theory relating to stress}

While most parents of disabled children provide caring and safe homes for their children (Taylor et al., 2016), many disabled children require a greater amount of care than their non-disabled peers. They can require a considerable amount of personal care and supervision and place significant practical and emotional demands on their parents (Peer and Hillman, 2014; Sidebotham et al., 2016). This can involve direct care such as feeding and toileting beyond a child's younger years; increased need for supervision; attendance to care and medical needs at regular intervals throughout the day and night; and frequent appointments at health services, with little prospect of improvements in the child's wellbeing, or respite from the task of caring. Parents can be subject to exhaustion from 'roundthe-clock care' (Nowak, 2015, p. 296) and have described,

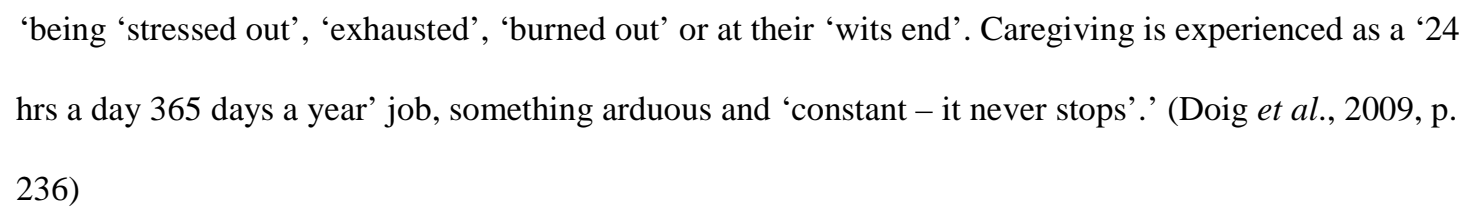

Families must also balance the requirements of other members of the family, cover the costs required when bringing up a disabled child, and frequently report isolation and social difficulties (Findler et al., 2016).

This article is protected by copyright. All rights reserved. 
Whereas parents of disabled children in general experience high degrees of stress (Davis and Carter, 2008; Peer and Hillman, 2014), mothers are typically the main caregivers for children, and as such they can be especially prone to stress when raising a disabled child (Findler et al., 2016; Nes et al., 2014). This can affect their mental health, with mothers of disabled children found to experience greater psychological distress and to have an elevated risk for clinical depression [PUBLISHER - THE PRECEDING UNDERLINED TEXT IS FOR THE MARGIN, i.e. 'Mothers of disabled children [have been] found to experience greater psychological distress and to have an elevated risk for clinical depression'] compared to mothers of children with no disability (Nes et al., 2014). Mothers caring for children with autism, in particular, have been found to have high levels of mental health problems (Fairthorne et al., 2016; Sawyer et al., 2010). In fact, higher levels of stress and indicators of emotional difficulties have been reported for parents of children with autism than for either parents of children with other disabilities or parents of non-disabled children (Davis and Carter, 2008). This theory proposes that the stresses experienced by these parents lead to parental behaviours (such as violent outbursts) which can result in the death of the child.

\section{Theory relating to altruistic intent}

The second theory focuses on altruistic intent. In his seminal paper proposing a typology of filicide Resnick (1969, p. 329) proposes two forms of altruistic filicide: Firstly, 'filicide associated with suicide' committed by parents who claimed that they 'could not abandon their children' when they sought to die by suicide; and, secondly, 'filicide to relieve 
suffering' where the parent's aim was to alleviate the victim's suffering, which may have been real or imagined. Friedman et al. (2005) found that parents who killed their children and then died by suicide had a high incidence of mental illness, and although some cases involved a psychotic delusion that the child was suffering, others included children with genuinely serious medical conditions.

\section{Theory relating to lack of bond with child}

According to Nowak (2015), parent-child bonding is vital in preventing child abuse, however in the case of disabled children it is frequently weakened because of the need for intensive care for the children as neonates or due to repeated stays in hospital. Parents may also experience grief reactions due to the 'loss of the expected child' (Nowak, 2015, p. 296).

It is recognised that the birth of a disabled child can affect parental psychological wellbeing and life satisfaction (Nes et al., 2014; Fairthorne et al., 2015). In such circumstances, the bonding between a disabled child with either or both parents can be compromised (Palermo, 2003), particularly for children who find it difficult to express certain emotional responses, such as children with autism (Coorg and Tournay, 2012; Palermo, 2003). Barone et al. (2014) have also reported that problematic attachment relationships were overrepresented among a group of filicidal mothers.

\section{Theory relating to children with challenging behaviours}

This article is protected by copyright. All rights reserved. 
While younger children are more likely to be victims of homicide, murders also occur among older children (UNICEF, 2003). Parents may become frustrated with lack of response to conventional disciplinary methods and progressively turn to harsher punishments (Nowak, 2015). In instances where parents may be challenged by the behaviour of their child, some parents may use excessive force, resulting in the child's death [PUBLISHER - THE PRECEDING UNDERLINED TEXT IS FOR THE MARGIN]. As well as adolescents who are testing boundaries, children with autism are seen as part of this higher risk group due to the nature of their behaviour and a parent's sense of frustration at being unable to care for and control their child (Coorg and Tournay, 2012).

\section{Theory relating to disabled children and cultural beliefs}

There has been a growing awareness of the death of children due to cultural beliefs about disabled children. For example, in the African context, Assouan et al. (2014) report that there is stigma surrounding facial clefts, often leading to rejection or infanticide of the affected newborn. Similarly, Denham et al. (2010) report that in the Kassena-Nankana District of Ghana, investigators have described situations whereby some children die by infanticide as they are considered 'spirit children' sent 'from the bush' to cause calamity to the family. Some disabled children are seen as such spirit children, thus increasing their risk of being killed.

\section{Theory relating to evolutionary imperatives}

This article is protected by copyright. All rights reserved. 
Seminal research by Daly and Wilson (1988), proposes that specific patterns of parental inclination have evolved in mothers that lead them to commit infanticide, as the child would have been 'unlikely to survive during human evolutionary history' (p. 522). In such situations, mothers are typically relatively young and have considerable continued capacity for reproduction, but rearing a child with difficulties, such as a disabled child, could jeopardise their own survival and future opportunities to have further children. According to this theory, in a similar way to other mammals, the forces of evolution in distant eras have formed mothers' emotional responses, behaviours and motivations to be 'disinclined to raise (such) a child' (Daly and Wilson, 1988, p. 521).

In order to, firstly, develop greater knowledge of risk factors related to the homicides and maltreatment-related deaths of disabled children and, secondly, evaluate the support for the explanatory theories posited, the aim of this article is to systematically review the empirical literature relating to the deaths of disabled children intentionally (homicide), or through maltreatment. In doing so we intend to add to the understanding of this phenomenon and to support policy and practice responses.

\section{Methods}

This article is protected by copyright. All rights reserved. 


\section{Retrieval and selection of articles}

Within a larger systematic search of literature regarding child homicide, the current review is focused on the deaths of disabled children through either (a) intentional filicides; (b) deaths directly caused by abuse or neglect (either one-off incidents, or the culmination of chronic maltreatment); or (c) deaths where abuse and neglect may have contributed but were not the primary cause of death. We identified relevant articles in peer-reviewed journals through systematic searches in six electronic databases: AMED, CINAHL, Criminal Justice Abstracts, Medline (PubMed), PsycINFO and SCOPUS. We used the following search terms to retrieve relevant articles: (homicide OR murder OR manslaughter OR filicide OR infanticide OR neonaticide OR filicide-suicide OR familicide OR fatal child abuse OR fatal child maltreatment OR death OR kill OR fatality) AND (victim OR child OR infant OR baby OR toddler OR pre-schooler OR adolescent OR teenager) AND (perpetrator OR parent OR mother OR father OR step-parent OR biological parent OR carer OR guardian OR fosterparent OR partner OR de facto OR paramour OR boyfriend OR girlfriend OR baby-sitter OR child-minder OR spouse OR friend OR stranger OR murderer OR killer). Additionally, we checked references in related review articles. We confined our searches to peer-reviewed articles published in English between January $1^{\text {st }}, 1990$ and December $31^{\text {st }}, 2017$ [PUBLISHER - THE PRECEDING UNDERLINED TEXT IS FOR THE MARGIN].

To assess the evidence base for the theories described in the introduction, we aimed to review empirical work only rather than opinion pieces or other reviews. Therefore, articles were included in our final selection only if they involved: (a) the collection of empirical data regarding (b) homicide or maltreatment-related deaths of (c) one or more people younger 
than 18 years old, of whom (d) at least one was described as disabled, or where the article explicitly considered disabled children in its assessment.

Figure 1 shows the screening and selection flowchart. JF and JD carried out screening and selection by consensus, with EA screening a subset of the papers as an additional check (no discrepancies found).

\section{- Please insert Figure 1 about here -}

\section{Coding and analysis}

We identified and recorded information obtained in a standardised form. Initial coding was undertaken by JF and JD. Discussion regarding this coding then took place among all three authors until consensus was reached. We extracted information in three domains. Firstly, the design and methods were recorded. We included a brief description of the design and any standardised definitions and measures that were used. Secondly, we summarised the sample in relation to demographics, location and size of the sample. Thirdly, all information for the sample in relation to disabled children and whether this was thought to be relevant to the reason for their death was noted. As the number of relevant articles was so small and the approaches so diverse, we opted to describe all relevant information. As a consequence, our findings are tentative, given the small number and wide variation of the included articles.

\section{Findings}


Our initial search resulted in 535 potentially eligible articles, of which 25 met our criteria. The included articles described 5150 child homicides and maltreatment-related deaths [PUBLISHER - THE PRECEDING UNDERLINED TEXT IS FOR THE MARGIN], ranging from an article describing a single case to much larger samples of over 2000 cases (see Table 1 for an overview). Most $(\mathrm{n}=10)$ of the included articles drew upon data from the USA; four from the UK; two each from Australia, Italy, and Sweden, and single papers with data from Belgium, Canada, China, Finland, France and Turkey. The designs varied significantly, with 21 being case series, one a single case and three epidemiological studies. The vast majority (23) did not have specific hypotheses regarding disability.

- Please insert Table 1 about here -

The articles fell into three broad categories: firstly, those primarily focused on the perpetrators; secondly, those focusing mainly on the children; and thirdly, articles which explored the characteristics and circumstances of both perpetrators and victims (See Table 1).

\section{Risk factors}

The first aim of the review was to gain greater understanding of the risk factors regarding the homicides and maltreatment-related deaths of disabled children. Those found in these particular articles and described below included: parental failure to provide $\underline{\text { care/standard of care; parental lack of access to services; parental mental illness; and children }}$ with autism [PUBLISHER - THE PRECEDING UNDERLINED TEXT IS FOR THE 
MARGIN, i.e. '[Risk factors] included: parental failure to provide care/standard of care; parental lack of access to services; parental mental illness; and children with autism'].

\section{Parental failure to provide care}

Sidebotham et al. (2011), in an analysis of reports into the death or serious injury of 276 children, identified five disabled children where natural causes had led to the child's death, but with a suggestion of parental failure to effectively deal with the child's illness and/or care needs. The article by Jonson-Reid et al. (2007) reported a link between health risks in infancy and future death, stating that there is a need to be clear about whether deaths of disabled children are more attributable to their disability/illness than to maltreatment, particularly when the cause of death may result from the standard of care provided (or not provided) by a parent or caregiver. In the article by Rougé-Maillart et al. (2005), a mother confined her disabled child in a room and deprived him of food and water until he died. Neglect by parents leading to death by starvation for a disabled child was also reported in the article by $\operatorname{Sim}(2015)$.

\section{Parental lack of access to services}

Palusci and Covington (2014), in an analysis of 49947 child deaths in the USA identified 2285 cases where child abuse resulted in or was a contributing factor in the death. They identified that $341(13.7 \%)$ of the children had a 'prior disability/chronic illness' recorded, of whom 223 suffered neglect, 121 suffered physical abuse and 10 suffered psychological maltreatment. They concluded that the high number of children with previous 
disability or chronic illness emphasised the importance of parents having access to interventions and services for the additional needs of both carers and children in these situations.

\section{Parental mental illness}

Coorg and Tournay (2013) studied 22 children with developmental disabilities who were victims of filicide-suicide. There were 21 offenders of whom 10 were fathers, 10 were mothers, and one was a grandfather. Over a third (38\%) of the offenders were reported as having a mental illness, which included depression, bipolar disorder and psychosis. Nordlund and Temrin (2007) found that three of five offenders died by suicide in connection with the homicides, of whom two had psychiatric illnesses. In Marleau et al. (1999), a 14-month-old child was killed by her father when he was experiencing a psychotic episode. The issue of a parent's or carer's poor mental health and the death of children, including disabled children, was also noted by McKee and Bramante (2010), who reported that children who were medically and mentally unwell were at greater risk of homicide when their mother had a mental illness.

\section{Children with autism}

A number of articles noted autism as a specific disability that appears to be associated with homicide in certain circumstances. Coorg and Tournay (2013) found that 55 per cent of the disabled child victims of filicide-suicide were diagnosed with autism spectrum disorder. The child in Declercq et al. (2017) also had autism, which was seen as a factor leading to him 
being chosen as a victim. Sim (2015), too, in the case noted earlier, described a seven-yearold disabled girl with autism, who died from starvation and neglect on the part of her parents.

\section{Definition of disability}

An important factor pertinent to helping understand the homicides and maltreatmentrelated deaths of disabled children was the definition of disability employed. Most articles did not state how they defined disability [PUBLISHER - THE PRECEDING UNDERLINED TEXT IS FOR THE MARGIN]. Among those that did define it, the definitions varied from the very broad to the more specific. Coorg and Tournay (2013, p. 745) defined chronic disability as 'any long term sensory, physical, or mental state that could interfere with selfcare as a child ages'. Some articles framed disability in terms of medical diagnoses, for example, 'trisomy 21' (Rougé-Maillart et al., 2005, p. 324). In most articles, disability involved the use of a wide range of terms and nomenclatures, for example, developmental delay/concerns/issues, learning difficulties, autism, mental illness, or behavioural disorders/disturbance/problems.

\section{Support for theories for increased risk of homicide}

This article is protected by copyright. All rights reserved. 
The second aim of the review was to provide a reflection on the evidence to support any of the theories proposed to explain the increased risk of homicides and maltreatmentrelated deaths to disabled children.

\section{Theory relating to stress}

In Harper and Voigt (2007, p. 305), the authors described a case which appeared to explain the homicide as being motivated by the stress involved in caring for a disabled child. The mother killed her two children and then herself, leaving a series of notes saying, 'she is 'tired' and worn out by caring for her 8-year-old severely mentally handicapped daughter'. The article by Coorg and Tournay (2013) suggested that certain types of disabled children, such as children with autism, may place a greater stress on carers. Stress was also noted in the article by Miller et al. (2007) regarding the homicide of internationally adopted children. They observed that these children can have complex behavioural problems such as reactive attachment disorder, with reports also of violent outbursts on the part of the children. They highlighted the vigilance required by professionals in identifying parents or carers who may be showing signs of disappointment, stress, or depression when adopting children in these circumstances. Hegar et al. (2015) also noted a significant degree of stress among those parents with internationally adopted children.

Theory relating to altruistic intent 
Rougé-Maillart et al. (2005) outlined two cases they described as altruistic homicides. In the first a mother killed her two-year-old son. When questioned, she said that life 'would be too hard for him if he did not know how to speak' (p. 324), even though he was just 18 months old. In the second case, a couple had decided to put their son into a centre for disabled children, although subsequently the boy's mother said she could not bear this idea. The child, who had Down Syndrome, was locked in a room by his mother and deliberately deprived of food and water until he died. Marleau et al. (1999) reported a case where the motivation appeared to be altruism. A father killed his youngest daughter to prevent her from becoming like her older sister, who was significantly disabled and who died after being in a coma for a long period. The killing occurred when the younger daughter was 14 months old and her father was experiencing a psychotic episode. The article was not clear whether the child who was murdered was actually disabled. Nordlund and Temrin (2007) reported that the deaths of five disabled children were seen as 'acts of mercy'. The children were experiencing illness and the perpetrators were deemed to be 'saving' them from further suffering. Three of the five offenders died by suicide in connection with these homicides; none of the offenders killed any other family members; two of the perpetrators had psychiatric illnesses; and one had social difficulties. In Eriksson et al. (2016, p. 25), a mother killed her son who was chronically physically disabled because he had 'been through enough, I saw him hurting so much'. Coorg and Tournay (2013) suggested that parents of autistic children, when feeling depressed and at risk for suicide, may consider filicide as altruistic. While the perceived intention may have appeared altruistic, these cases could also be seen as representing parents 


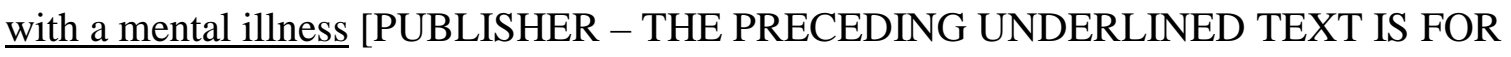
THE MARGIN].

Theory relating to children with challenging behaviours

Coorg and Tournay (2013) indicated that autistic children can be liable to volatile behaviour which may place them at risk for physical maltreatment, which could result in a fatality. Miller et al. (2007) referred to challenging behaviour in their article regarding internationally adopted children with complex behavioural problems. Hegar et al. (2015) also described acute special needs and challenging behaviours associated with internationally adopted children.

\section{Theory relating to lack of bond with child}

There was only one article which referred to the theory regarding the lack of bond with a disabled child. Difficulties in bonding with a child with autism were noted by Coorg and Tournay (2013).

\section{Theories with no support}

In this review, there was no support found for the theories relating to cultural beliefs or evolutionary imperatives [PUBLISHER - THE PRECEDING UNDERLINED TEXT IS FOR THE MARGIN] for the increased risk of homicides and maltreatment-related deaths for disabled children. This is not to say that these theories are baseless, rather that the currently available empirical research has not looked specifically at the deaths of disabled children 
through such a lens, even though there is a literature on child homicide related to culture and evolutionary imperatives (e.g. Miller, 1987; Mathews et al., 2013; Mishra et al., 2014).

\section{Discussion}

As noted by Sidebotham et al. (2016) and Mathews and Abrahams (2018), the pathway to harming a child, by either action or omission, involves an interaction between the child and their vulnerabilities, the perpetrator and their situation, and the wider environmental context within which the human actors find themselves. The articles reviewed in the current paper show such a pathway, with reported risk factors related to the child (for example, type of disability, such as autism), risk factors associated with the perpetrator (for example, family stress, mental illness), and risks linked with the environment (for example, lack of services).

The theory relating to stress and the theory relating to altruistic intent were the two most common explanations cited for the homicides and maltreatment-related deaths of disabled children in the articles reviewed [PUBLISHER - THE PRECEDING UNDERLINED TEXT IS FOR THE MARGIN, i.e. 'Stress... and altruistic intent were the two most common explanations cited for the homicides and maltreatment-related deaths of disabled children in the articles reviewed'] . Both theories also have considerable support in the articles cited in the literature review in the introduction. Specifically, parents have more physical, economic and emotional demands upon them when their child is disabled. In turn this can increase the sense of being overwhelmed, stressed and isolated. In addition, this review lends support to the position by Camperio Ciani and Fontanesi (2012) that in instances 
where children have significant disabilities, a parent may not be mentally ill when they seek to relieve the suffering of their child, and may be making a rational decision, albeit one that is unpalatable. However, the evidence we have found is limited, and more research is required to explore the interaction between altruistic intent and parental psychopathology.

There appeared to be some support for the theory relating to children with challenging behaviours and for the theory relating to lack of bond, but no evidence for the theory around cultural beliefs nor the evolutionary theory. Although there is a possibility that the deaths of internationally adopted children may have some explanation on the basis of evolutionary theory and parental disinclination to raise children with difficulties, including those not biologically related, we feel that the theories relating to stress and challenging behaviours, as suggested by Hegar et al. (2015) and Miller et al. (2007) provide more suitable explanations.

These theories should not necessarily be seen as discrete and disconnected, however. In the case described by Declercq et al. (2017, p. 45) a 'critical interplay' was seen to have occurred between the disability of the victim and the personality disorder of the offender. A number of theories, operating in combination, may provide a fuller explanation of these complex events. For example, Coorg and Tournay (2013) refer to four of the theoretical explanations in relation to children with particularly demanding care needs. Firstly, they propose that certain types of disabled children, such as those with autism, may place greater stress on carers. Next, they note the difficulty of bonding with a child with autism. They also indicate that autistic children can be liable to volatile behaviour which may put them at risk for physical maltreatment, with possible fatal outcomes. Finally, they suggest that carers may consider as altruistic the carrying out of filicide in such difficult circumstances. 
Some of the articles reviewed have highlighted that while some disabled children have died as a result of violence directed at them, others have died either as a result of general neglect of their care and health needs (Sidebotham et al., 2011), or neglect with the deliberate intention of causing death [PUBLISHER - THE PRECEDING UNDERLINED TEXT IS FOR THE MARGIN, i.e. 'While some disabled children have died as a result of violence..., others have died either as a result of general neglect..., or neglect with the deliberate intention of causing death'] (Rougé-Maillart et al., 2005). Golden et al. (2003, p. 105) have noted the issue of 'deliberate or malicious failure to supply the needs of a child' which they term as 'deprivational abuse'. This intention may be a specific form of harm directed at and experienced by disabled children. Interventions to identify and meet the needs of children in such circumstances must be designed to differentiate between some parents' lack of understanding of, or inability to meet, or a combination of both, in relation to their child's needs, and other situations whereby carers are more intent on harming the child, even if the reason might be perceived as altruistic. This highlights the challenges for both practitioners involved in supporting a disabled child and their family, and also professionals involved in investigating a disabled child's death.

The issue of a child being disabled is recognised as a characteristic of a child and/or a factor worthy of note by some researchers looking at the homicides and maltreatment-related deaths of children. It is identified as a risk factor in most of the articles reviewed. However, the definition of the term 'disability' was not consistent, varying from the broad to the more specific. There was no single definition in use generally in the reviewed papers, which is also reflected within the relevant professional, scientific and academic communities. This 
provides a significant barrier in seeking to quantify and understand the scale and nature of homicides and maltreatment-related deaths involving disabled children. At the most fundamental level it would appear necessary that the nature of any disability of a child at the time of their death is recorded consistently by child death review processes and review teams. As noted by Palusci and Covington (2014), some data are routinely recorded in certain countries or regions, but this is quite limited, and would benefit from a global approach given the relatively small numbers of disabled children killed. An example of an approach which could be taken is provided by Kelly and Dowling (2015), where they note that an agreed definition of disability is needed to address the issue of underreporting of disabled children in child protection statistics and to promote consistency in recording disability. They have outlined an operational definition of disability, based on the UK Disability Discrimination Act 1995 as 'a physical or mental impairment that has substantial or long-term effect on a person's ability to carry out normal day-to-day activities' (Kelly and Dowling, 2015, p. 8). They state that the UK Autism Act 2011 'further amended this definition of disability to include social and communication impairments related to autistic spectrum conditions' (Kelly and Dowling, 2015, p. 4). They comment further that training for professionals could be made available to improve understanding of disability and emphasise the importance of information regarding disability being recorded to enable 'assessment and monitoring of the population of disabled children in contact with the child protection system' (Kelly and Dowling, 2015, p. 30).

\section{Policy and practice implications}


We could certainly do better in quantifying and understanding the homicides and maltreatment-related deaths of disabled children. There is a clear and pressing need for data on disabled children to be routinely collected and collated through existing child death review processes and the criminal justice system [PUBLISHER - THE PRECEDING UNDERLINED TEXT IS FOR THE MARGIN]. Not only would this help us to better understand this phenomenon, but it would also allow us to have fuller discussion about whether the deaths of disabled children are treated as seriously as the deaths of non-disabled children.

Sidebotham et al. (2016) and Mathews and Abrahams (2018) have commented that adopting a more ecological rather than pathological perspective holds out a greater prospect of intervening in ways that are likely to reduce the incidence of maltreatment deaths and 'clear coordinated care pathways for families with particular vulnerabilities are needed to help ensure parents and children receive timely and accessible help' (Sidebotham et al., 2016, p. 17). Improved professional awareness of the needs of disabled children and understanding that these needs may not coincide with those of their parents or carers (Jones et al., 2017; Stalker et al., 2015; Taylor et al., 2015), appears vital for the protection from harm of these vulnerable children.

There is a need for the incorporation into adult mental health professionals and services a consciousness of the needs of the children of their clients, especially of vulnerable disabled children. There were clear risks for children among some of the parents with mental illness in the articles reviewed, including suicidal behaviour and the inclusion of children in psychotic delusions (Coorg and Tournay, 2013; Marleau et al., 1999; McKee and Bramante, 
2010; Nordlund and Temrin, 2007). However, parents can sometimes be treated by adult mental health services without consideration of their family context and of the needs of their children (Brandon et al., 2012).

Parents frequently experience stress during the assessment and diagnostic process involving their disabled child, with clear evidence that open, honest and positive experiences with health professionals at this crucial time, including the provision of support and counselling, can have important consequences for their ongoing coping capacity (The Royal Australasian College of Physicians - Paediatric and Child Health Division, 2013). The high care demands on parents of disabled children (Peer and Hillman, 2014; Sidebotham et al., 2016), and consequent exhaustion (Doig et al., 2009; Nowak, 2015), stress (Davis and Carter, 2008; Peer and Hillman, 2014) and isolation (Findler et al., 2016) also mean that opportunities for respite or 'short breaks' can be vital in enabling parents continue their task of caring (Collins et al., 2014, p. 1180).

\section{Limitations}

There are several limitations to this review. Firstly, our systematic search yielded only a small number of relevant articles. This suggests that there is a need for further research but also limits our current conclusions. In addition, the research designs varied considerably, and disability was often not central to the research questions; while providing some valuable insights, this diversity limits the potential for comparisons. Finally, any systematic review is 
limited by decisions made regarding scope and design. For example, for feasibility reasons, we only included English language papers; it is possible that peer-reviewed work has been published in other languages.

\section{Conclusion}

In conclusion, in this review regarding homicides and maltreatment-related deaths of disabled children, a range of potential risk factors emerged, related to the child, the perpetrator and the environment, with the pathway to harming the child involving an interactive process between each of these. Type of disability, such as autism, family factors such as stress and mental illness, and risks associated with the environment, such as lack of services were evident. Theoretical explanations related to stress and altruistic intent were more commonly used and supported than explanations related to challenging behaviours, a lack of bonding, cultural beliefs and evolutionary imperatives, although a combination of theories may provide a more comprehensive explanation of these complex events. The overarching message is that we still have limited evidence about the specific risks involved in the homicides and maltreatment-related deaths of disabled children [PUBLISHER - THE PRECEDING UNDERLINED TEXT IS FOR THE MARGIN], and greater international cooperation about how we record such information would assist as we move forward.

\section{References}

This article is protected by copyright. All rights reserved. 
Assouan C, Anzouan-Kacou E, Ahoussou EM, Kpebo D Tanon-Anoh M-J, Konan E. 2014. Advantages of early management of facial clefts in Africa. International Journal of Pediatric Otorhinolaryngology 78(3): 504-506. https://doi.org/10.1016/j.ijporl.2013.12.031

Barone L, Bramante A, Lionetti F, Pastore M. 2014. Mothers who murdered their child: An attachment-based study on filicide. Child Abuse \& Neglect 38, 1468-1477.

Brandon M, Sidebotham P, Bailey S, Belderson P, Hawley C, Ellis C, Megson M. 2012. New learning from serious case reviews. DFE-RR226. Department for Education: London.

Camperio Ciani ASC, Fontanesi L. 2012. Mothers who kill their offspring: Testing evolutionary hypothesis in a 110-case Italian sample. Child Abuse \& Neglect 36(6): 519-527. https://doi.org/10.1016/j.chiabu.2012.05.001

Chance T, Scannapieco M. 2002. Ecological correlates of child maltreatment: Similarities and differences between child fatality and nonfatality cases. Child and Adolescent Social Work Journal 19(2): 139-161.

Collins M, Langer S, Welch V, Wells E, Hatton C, Robertson J, Emerson E. 2014. A break from caring for a disabled child: Parent perceptions of the uses and benefits of short break provision in England. British Journal of Social Work 44: 1180-1196. https://doi.org/10.1093/bjsw/bcs209

Coorg R, Tournay A. 2013. Filicide-suicide involving children with disabilities. Journal of Child Neurology 28(6): 745-751. https://doi.org/10.1177/0883073812451777

Davis NO, Carter AS. 2008. Parenting stress in mothers and fathers of toddlers with autism spectrum disorders: Associations with child characteristics. Journal of Autism and Developmental Disorders 38: 1278-1291. https://doi.org/10.1007/s10803-007-0512-Z

Daly M, Wilson M.1988. Evolutionary social psychology and family homicide. Science 242 (4878): 519-524.

This article is protected by copyright. All rights reserved. 
Declercq F, Meganck R, Audenaert K. 2017. A case study of paternal filicide-suicide: Personality disorder, motives, and victim choice. The Journal of Psychology 151(1): 36-48. https://doi.org/10.1080/00223980.2016.1211983

Denham AR, Adongo PB, Freydberg N, Hodgson A. 2010. Chasing spirits: Clarifying the spirit child phenomenon and infanticide in Northern Ghana. Social Science \& Medicine 71(3): 608-615. https://doi.org/10.1016/j.socscimed.2010.04.022

Densley JA, Hilal SM, Li SD, Tang W. 2017. Homicide-suicide in China: An exploratory study of characteristics and types. Asian Criminology 12: 199-216. https://doi.org/10.1007/s11417016-9238-1

Doig JL, McLennan JD, Urichuk L. 2009. 'Jumping through hoops': Parents' experiences with seeking respite care for children with special needs. Child: Care Health and Development 35: 234-242. https://doi.org/10.1111/j.1365-2214.2008.00922.x

Douglas EM. 2014. A comparison of child fatalities by physical abuse versus neglect: Child, family, service, and worker characteristics. Journal of Social Service Research 40(3): 259-273. https://doi.org/10.1080/01488376.2014.893948

Douglas EM, Mohn BL. 2014. Fatal and non-fatal child maltreatment in the US: An analysis of child, caregiver, and service utilization with the National Child Abuse and Neglect Data Set. Child Abuse \& Neglect 38(1): 42-51. https://doi.org/10.1016/j.chiabu.2013.10.022

Eke SM, Basoglu S, Bakar B, Oral G. 2015. Maternal filicide in Turkey. Journal of Forensic Sciences 60: S143-S151. https://doi.org/10.1111/1556-4029.12560

Eriksson L, Mazerolle P, Wortley R, Johnson H. 2016. Maternal and paternal filicide: Case studies from the Australian Homicide Project. Child Abuse Review 25(1): 17-30. https://doi.org/10.1002/car.2358

Fairthorne J, Jacoby P, Bourke J, de Klerk N, Leonard H. 2015. Onset of maternal psychiatric disorders after the birth of a child with intellectual disability: A retrospective cohort study. 
Journal of Psychiatric Research 61: 223-230.

https://doi.org/10.1016/j.jpsychires.2014.11.011

Fairthorne J, Jacoby P, Bourke J, de Klerk N, Leonard H. 2016. Onset of maternal psychiatric disorders after the birth of a child with autism spectrum disorder: A retrospective cohort study. Autism 20(1): 37-44. https://doi.org/10.1177/1362361314566048

Findler L, Jacoby AK, Gabis L. 2016. Subjective happiness among mothers of children with disabilities: The role of stress, attachment, guilt and social support. Research in Developmental Disabilities 55: 44-54. https://doi.org/10.1016/j.ridd.2016.03.006

Friedman SH, Hrouda DR, Holden CE, Noffsinger SG, Resnick PJ. 2005. Filicide-suicide: Common factors in parents who kill their children and themselves. The Journal of the American Academy of Psychiatry and the Law 33(4): 496-504.

Golden MH, Samuels MP, Southall DP. 2003. How to distinguish between neglect and deprivational abuse. Archives of Disease in Childhood 88(2): 105-107. https:// doi.org/10.1136/adc.88.2.105

Harper DW, Voigt L. 2007. Homicide followed by suicide: An integrated theoretical perspective. Homicide Studies 11(4): 295-318. https://doi.org/10.1177/1088767907306993

Hegar RL, Verbovaya O, Watson LD. 2015: Child fatality in intercountry adoption: What media reports suggest about deaths of Russian children in the U.S. Children and Youth Services Review 55: 182-192. https://doi.org/10.1016/j.childyouth.2015.06.002

Jones C, Stalker K, Franklin A, Fry D, Cameron A, Taylor J. 2017. Enablers of help-seeking and protection from abuse for deaf and disabled children: A qualitative study. Child \& Family Social Work 22(2): 762-771. https://doi.org/10.1111/cfs.12293

Jones L, Bellis MA, Wood S, Hughes K, McCoy E, Eckley L, Bates G, Mikton C, Shakespeare T, Officer A. 2012. Prevalence and risk of violence against children with disabilities: A systematic review and meta-analysis of observational studies. The Lancet 380: 899-907. https://doi.org/10.1016/ S0140-6736(12)60692-8 
Jonson-Reid M, Chance T, Drake B. 2007. Risk of death among children reported for nonfatal maltreatment. Child Maltreatment 12(1): 86-95.https://doi.org/10.1177/1077559506296722

Kajese TM, Nguyen LT, Pham GQ, Pham VK, Melhorn K, Kallail KJ. 2011. Characteristics of child abuse homicides in the state of Kansas from 1994 to 2007. Child Abuse \& Neglect 35(2): 147-154. https://doi.org/10.1016/j.chiabu.2010.11.002

Kauppi A, Kumpulainen K, Karkola K, Vanamo T, Merikanto J. 2010. Maternal and paternal filicides: A retrospective review of filicides in Finland. The Journal of the American Academy of Psychiatry and the Law 38(2): 229-238.

Kelly B, Dowling S. 2015. Safeguarding disabled children and young people: A scoping exercise of statutory child protection services for disabled children and young people in Northern Ireland. Queen's University and the Safeguarding Board for Northern Ireland: Belfast.

Kemp AM, Mott AM, Sibert JR. 1994. Accidents and child abuse in bathtub submersions. Archives of Disease in Childhood 70(5): 435-438.

Koenen M, Thompson J. 2008. Filicide: Historical review and prevention of child death by parent. Infant Mental Health Journal 29(1): 61-75. https://doi.org/10.1002/imhj.20166

Lee CK, Lathrop SL. 2010. Child abuse related homicides in New Mexico: A 6 resteaspective review. Journal of Forensic Sciences 55(1): 100-103. https://doi.org/10.1111/j.15564029.2009.01253.x

Marleau JD, Poulin B, Webanck T, Roy R, Laporte L. 1999. Paternal filicide: A study of 10 men. The Canadian Journal of Psychiatry 44(1): 57-63.

Mathews S, Abrahams N. 2018. Developing an Understanding of Filicide in South Africa. In: When Parents Kill Children, Brown T, Tyson D, Fernandez Arias P (eds). Palgrave Macmillan: Cham, Switzerland; pp. 43-61. https://doi.org/10.1007/978-3-319-63097-7_3

Mathews S, Abrahams N, Jewkes R, Martin LJ, Lombard C. 2013. The epidemiology of child homicides in South Africa. Bulletin of the World Health Organization 91: 562-568. 
McKee GR, Bramante A. 2010. Maternal filicide and mental illness in Italy: A comparative study. The Journal of Psychiatry \& Law 38(3): 271-282.

Miller BD. 1987. Female infanticide and child neglect in rural North India: In: Child Survival, Scheper-Hughes N (ed). Springer: Dordrecht; pp. 95-112.

Miller LC, Chan W, Reece RA, Tirella LG, Pertman A. 2007. Child abuse fatalities among internationally adopted children. Child Maltreatment 12(4): 378-380. https://doi.org/10.1177/1077559507306716

Mishra K, Ramachandran S, Kumar A, Tiwari S, Chopra N, Datta V, Saili A. 2014. Neonaticide in India and the stigma of female gender: Report of two cases. Paediatrics and International Child Health, 34(3): 224-226. https://doi.org/10.1179/2046905513Y.0000000076

Nes RB, Røysamb E, Hauge LJ, Kornstad T, Landolt MA, Irgens LM, Eskedal L, Kristensen P, Vollrath ME. 2014. Adaptation to the birth of a child with a congenital anomaly: A prospective longitudinal study of maternal well-being and psychological distress. Developmental Psychology 50(6): 1827-1839. https://doi.org/10.1037/a0035996

Nordlund J, Temrin H. 2007. Do characteristics of parental child homicide in Sweden fit evolutionary predictions? Ethology 113(11): 1029-1037. https://doi.org/10.1111/j.14390310.2007.01412.x

Nowak CB. 2015. Recognition and prevention of child abuse in the child with disability. American Journal of Medical Genetics Part C (Seminars in Medical Genetics) 169(4): 293-301. https://doi.org/10.1002/ajmg.c.31458

Palermo M. 2003. Preventing filicide in families with autistic children. International Journal of Offender Therapy and Comparative Criminology 47(1): 47-57. https://doi.org/10.1177/0306624X02239274

Palusci VJ, Covington TM. 2014. Child maltreatment deaths in the U.S. National Child Death Review Case Reporting System. Child Abuse \& Neglect 38(1): 25-36. https://doi.org/10.1016/j.chiabu.2013.08.014 
Peer J, Hillman S. 2014. Stress and resilience for parents of children with intellectual and developmental disabilities: A review of key factors and recommendations for practitioners. Journal of Policy and Practice in Intellectual Disabilities 11(2): 92-98.

Resnick PJ. 1969. Child murder by parents: A psychiatric review of filicide. American Journal of Psychiatry 126(3): 325-34.

Rougé-Maillart C, Jousset N, Gaudin A, Bouju B, Penneau M. 2005. Women who kill their children. The American Journal of Forensic Medicine and Pathology 26(4): 320-326. https://doi.org/10.1097/01.paf.0000188085.11961.b2

Sawyer MG, Bittman M, La Greca AM, Crettenden AD, Harchak TF, Martin J. 2010. Time demands of caring for children with autism: What are the implications for maternal mental health? Journal of Autism and Developmental Disorders 40: 620- 628. https://doi.org/10.1007/s10803-009-0912-3

Sidebotham P, Bailey S, Belderson P, Brandon M. 2011. Fatal child maltreatment in England, 20052009. Child Abuse \& Neglect 35(4): 299-306. https://doi.org/10.1016/j.chiabu.2011.01.005

Sidebotham P, Brandon M, Bailey S, Belderson P, Dodsworth J, Garstang J, Harrison E, Retzer A, Sorensen P. 2016. Pathways to harm, pathways to protection: a triennial analysis of serious case reviews 2011 to 2014. Department for Education: London.

Sim J. 2015. Invisible children, dying to save others: A discussion of three fatal child abuse cases and the prevention of future deaths. Current Issues in Criminal Justice 27(1): 79-94.

Somander LK, Rammer LM. 1991. Intra-and extrafamilial child homicide in Sweden 1971-1980. Child Abuse \& Neglect 15(1-2): 45-55.

Stalker K, Taylor J, Fry D, Stewart A. 2015. A study of disabled children and child protection in Scotland - A hidden group? Children and Youth Services Review 56: 126-134. https://doi.org/10.1016/j.childyouth.2015.07.012

Taylor J, Cameron A, Jones C, Franklin A, Stalker K, Fry D. 2015. Deaf and disabled children talking about child protection. NSPCC Child Protection Research Centre: Edinburgh. 
Taylor J, Stalker K, Stewart A. 2016. Disabled children and the child protection system: A cause for concern. Child Abuse Review 25(1): 60-73. https://doi.org/10.1002/car.2386

The Royal Australasian College of Physicians - Paediatric and Child Health Division. 2013. Position Statement: Early Intervention for Children with Developmental Disabilities. Available: https://www.racp.edu.au/docs/default-source/advocacy-library/early-intervention-forchildren-with-developmental-disabilities.pdf [12 December 2018].

UNICEF. 2003. A league table of child maltreatment deaths in rich nations. Innocenti Report Card No. 5. UNICEF Innocenti Research Centre: Florence.

United Nations Convention on the Rights of People with Disabilities. 2007. Available: http://www.un.org/disabilities/documents/convention/convoptprot-e.pdf [3 May 2018].

Vincent S, Petch A. 2017. Understanding child, family, environmental and agency risk factors: Findings from an analysis of significant case reviews in Scotland. Child and Family Social Work 22(2): 741-750. https://doi.org/10.1111/cfs.12290

This article is protected by copyright. All rights reserved. 


\section{Figure 1}

13483 records identified through database searching (AMED 152, CINAHL 179, Criminal Justice Abstracts 1134, Medline (PubMed) 4,780, PsychINFO 3360, Scopus 3878

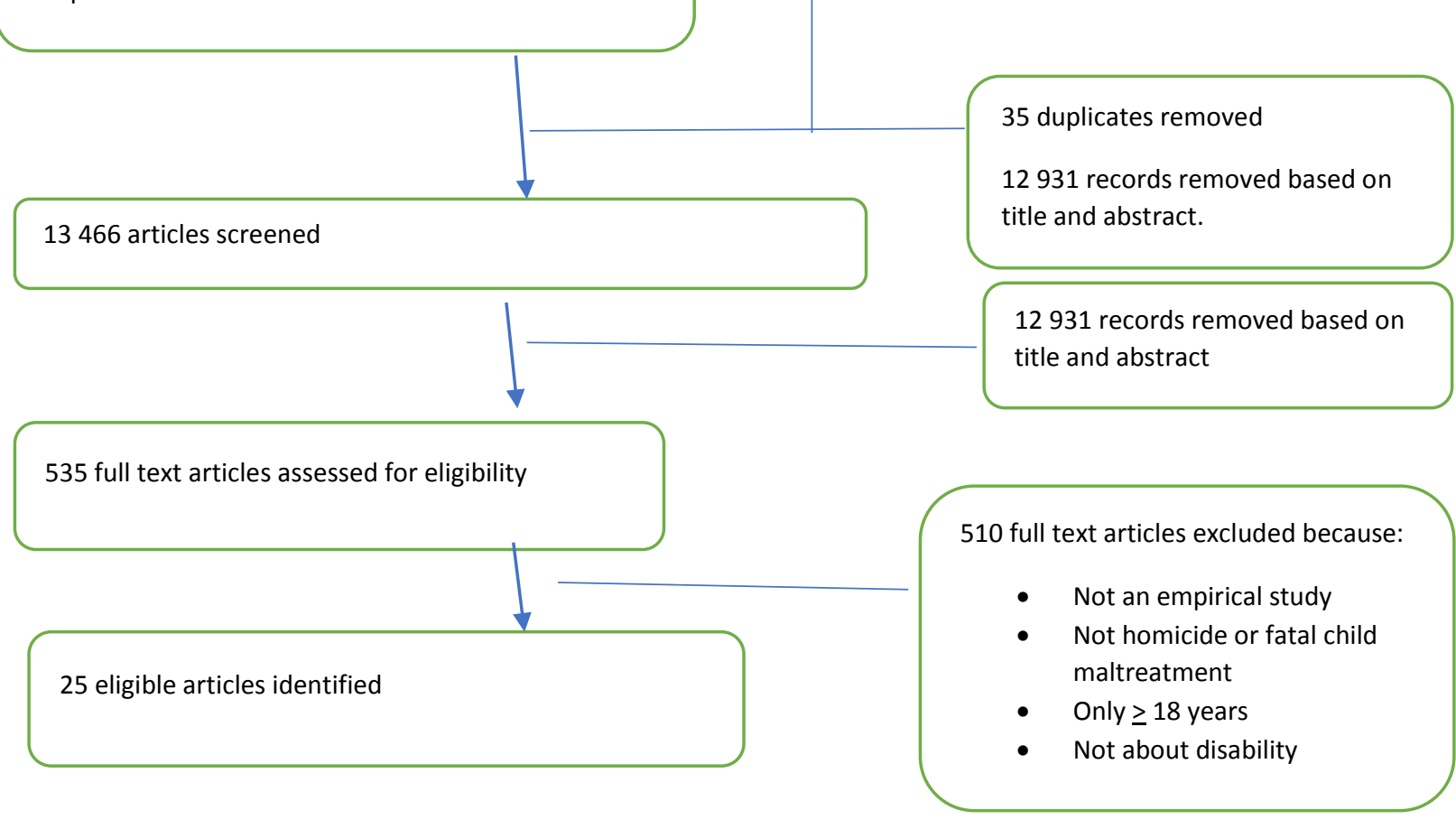




\section{University Library}

\section{- M M I N E R VA A gateway to Melbourne's research publications}

Minerva Access is the Institutional Repository of The University of Melbourne

Author/s:

Frederick, J;Devaney, J;Alisic, E

Title:

Homicides and Maltreatment-Related Deaths of Disabled Children: A Systematic Review

Date:

2019-09-05

Citation:

Frederick, J., Devaney, J. \& Alisic, E. (2019). Homicides and Maltreatment-Related Deaths of Disabled Children: A Systematic Review. CHILD ABUSE REVIEW, 28 (5), pp.321-338. https://doi.org/10.1002/car.2574.

Persistent Link:

http://hdl.handle.net/11343/286915 